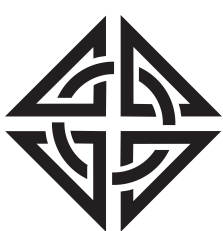

SCIENTIA
Sharif University of Technology

Scientia Iranica

Transactions C: Chemistry and Chemical Engineering

www.scientiairanica.com

\title{
Encapsulation of Keggin-type phosphotungstic acid into the mesopores of SBA-16 as a reusable heterogeneous catalyst for the epoxidation of olefins
}

\author{
M. Masteri-Farahani* and M. Modarres \\ Faculty of Chemistry, Kharazmi University, Tehran, Iran.
}

Received 28 February 2016; received in revised form 3 March 2017; accepted 18 September 2017

\section{KEYWORDS}

Mesoporous SBA-16;

Heteropoly acid;

Keggin;

Immobilization;

Epoxidation.

\begin{abstract}
A heterogeneous catalyst for the epoxidation of olefins was prepared by encapsulating Keggin-type phosphotungstic acid $\left(\mathrm{H}_{3} \mathrm{PW}_{12} \mathrm{O}_{40}\right)$ into the mesopores of SBA-16. After the encapsulation, the pore entrance size of SBA-16 was reduced through a silylation method to encompass the catalyst in the mesopores and allow easy diffusion of the reactants and products during the catalytic process. The prepared catalyst was characterized by FTIR and Inductively Coupled Plasma-Optical Emission Spectroscopies(ICP-OES), X-Ray Diffraction (XRD), and Transmission Electron Microscopy (TEM). The analysis results revealed that the mesoporous nature of SBA-16 was conserved after encapsulation of the catalyst following the silylation step. The catalytic activity of the prepared material was assessed in the epoxidation of olefins with $\mathrm{H}_{2} \mathrm{O}_{2}$. The heterogeneous catalyst was recovered and reused up to five cycles without considerable decrease in activity.
\end{abstract}

(C) 2017 Sharif University of Technology. All rights reserved.

\section{Introduction}

Polyoxometalates (POMs) are a prominent category of transition metal oxide anions, mostly vanadium, molybdenum, and tungsten with various structures [15]. The major utilization of these compounds is in the area of catalysis where soluble POMs exhibit the role of homogeneous catalysts in the oxidation of organic compounds [5-13]. It is well-known that POMs have fast and reversible redox properties, which make them hopeful catalysts for the oxidation of olefins, aromatics, and alcohols $[14,15]$. So far, due to the green chemistry considerations, many of these catalysts have been explored for the epoxidation of

*. Corresponding author. Tel./Fax: +982634551023, E-mail address: mfarahany@yahoo.com ( $M$. Masteri-Farahani)

doi: $10.24200 /$ sci. 2017.4492 olefins in the presence of hydrogen peroxide [15-18]. However, the troubles in separation and reuse of these homogeneous catalysts have restricted their large-scale applications in industrial syntheses. In addition, low specific surface area of these compounds in solid state has restricted the accessibility of their active sites and this decreases their catalytic activity in heterogeneous phase. Thus, immobilization of POMs into extremely porous materials is of great attention due to the facile separation and recovery of catalyst in practical uses. Encapsulation of catalytically active POMs into suitable porous supports is a useful approach for designing efficient heterogeneous catalysts and a variety of porous materials have been used for this purpose [19]. Metal-Organic Frameworks (MOFs) have been used as supports for the immobilization of POMs [20-25]. However, the difficulties in their preparation on the one hand and their low stability in some reaction media on the other hand have limited their wide utilization in heterogeneous catalysis. There are also some reports 
on the encapsulation of Keggin-type POMs into the supercages of zeolite Y [26-30]. But, as the size of the Keggin structures is larger than that of the pore entrance of zeolite $\mathrm{Y}$, they cannot enter pore channels and serious leaching of POMs into the reaction mixture has been observed, which leads to their poor reusability in catalytic uses [27].

As the size of the pore entrance must be sufficiently large to accommodate the POMs molecules into the pores of porous materials, many attempts have been made for the encapsulation of POMs inside the pores of some mesoporous materials, especially SBA15 [31-37] and MCM-41 [37-44]. The encapsulation of Keggin-type POMs inside the pores of mesoporous molecular sieves may provide active catalysts for desired reactions. However, the attachment of POMs to the mesopore walls takes place by means of very weak interaction of the POMs acidic protons with the silanol groups and gives rise to the leaching of the POMs when using these systems in polar solvents. Kozhevnikov and van Bekkum reported high catalytic activity of heteropoly acid-mesoporous systems for acid catalyzed reactions conducted in the liquid phase [4547]. Nevertheless, they indicated that during the reactions involving polar media, POMs were delivered from mesopores and the catalytic reaction continued in homogeneous phase. Considering the above-mentioned drawbacks, we want to report an efficient method for designing an active and stable heterogeneous epoxidation catalyst by encapsulating the POMs in the mesopores of SBA-16 material.

Recently, SBA-16 mesoporous material has attracted much attention as support of heterogeneous catalysts due to its uniform and large pores, high surface area, high thermal stability, and tunable pore size [48-52]. It has a three-dimensional cubic mesoporous structure and, due to its large nanocages, it is a promising support for the encapsulation of POMs. While the immobilization of POMs catalysts on mesoporous materials such as SBA-15 and MCM41 has been widely reported $[31,44]$, to the best of our knowledge, there are few reports devoted to the immobilization of POMs into the mesoporous SBA16 without investigating its catalytic activity and stability $[37,53,54]$.

In this work, Keggin-type 12-tungstophosphoric acid is confined in the nanocages of SBA-16 by encapsulation and reducing the pore entrance size through the silylation method. Since there are no covalent linkage and other strong interactions between the heteropoly acid and the wall surface, the encapsulated catalyst in the nanocages keeps its primary properties as much as possible. The prepared heterogeneous catalyst is used for the epoxidation of olefins in the presence of $\mathrm{H}_{2} \mathrm{O}_{2}$. Finally, the stability of the prepared heterogeneous catalyst in the reaction conditions is investigated.

\section{Experimental}

\subsection{Materials and methods}

Pluronic copolymer F-127 $\left(\mathrm{EO}_{106} \mathrm{PO}_{70} \mathrm{EO}_{106}\right)$ was purchased from Sigma-Aldrich. All of the other reagents were provided from Merck Company and used without additional purification. FT-IR spectra of the materials were acquired using Perkin-Elmer Spectrum RXI FTIR spectrometer. The amount of the polyoxometalate in samples was determined by Inductively Coupled Plasma-Optical Emission Spectrometry (ICP-OES) on VARIAN VISTA-MPX after dissolving the samples in hydrogen fluoride. The powder X-ray diffraction patterns of the synthesized materials were recorded on a SIEFERT XRD 3003 PTS diffractometer using $\mathrm{Cu} \mathrm{K} \alpha$ radiation (wavelength, $\lambda=0.154 \mathrm{~nm}$ ). Transmission Electron Microscopy (TEM) analysis was performed using a Philips EM $208 \mathrm{~S}$ instrument with an accelerating voltage of $100 \mathrm{kV}$. The reaction products of the catalytic tests were analyzed by gas chromatography (Agilent Technologies 6890N, HP-5 capillary column) with Flame Ionization Detector (FID) using helium as carrier gas.

\subsection{Preparation of the catalyst}

The SBA-16 mesoporous material and $\mathrm{H}_{3} \mathrm{PW}_{12} \mathrm{O}_{40}$ were synthesized according to the methods in the literature.49,5 The heterogeneous catalyst was prepared by the following method: $500 \mathrm{mg}$ of calcined SBA-16 was dispersed in a solution of $0.1 \mathrm{mmol} \mathrm{H}_{3} \mathrm{PW}_{12} \mathrm{O}_{40}$ in $10 \mathrm{ml}$ water and the mixture was stirred for $24 \mathrm{~h}$ at room temperature. The excess water was slowly vaporized and the solid dried in vacuum oven overnight at $100^{\circ} \mathrm{C}$. Based on the method in the literature [50], the modification and adjusting the pore entrance size of SBA-16 were performed by silylation reaction. The obtained solid was dispersed in $1.5 \mathrm{ml}$ dry toluene, followed by the addition of $1.25 \mathrm{ml}$ anhydrous pyridine and $5 \mathrm{mmol}$ triethoxyoctylsilane, and then refluxed for $24 \mathrm{~h}$ under nitrogen atmosphere. After filtration, the white precipitate was washed with $\mathrm{CH}_{2} \mathrm{Cl}_{2}$ to eliminate the unreacted triethoxyoctylsilane and then dried in vacuum overnight. The precipitate was soxhlet extracted with distilled water to remove the physisorbed polyoxometalate species and then dried in vacuum oven for $24 \mathrm{~h}$.

\subsection{Catalytic studies}

$100 \mathrm{mg}$ of catalyst (activated in vacuum oven at $120^{\circ} \mathrm{C}$ overnight) was dispersed in a solution of $8 \mathrm{mmol}$ of olefin in $10 \mathrm{ml}$ of acetonitrile. After addition of $1.5 \mathrm{ml}$ $30 \% \mathrm{H}_{2} \mathrm{O}_{2}(12.8 \mathrm{mmol})$ and isooctane $(8.75 \mathrm{mmol}$, as internal standard), the reaction mixture was refluxed under nitrogen atmosphere. Gas chromatography was employed to monitor the progress of the reaction in appropriate times. On the completion of the reaction, the catalyst was separated, washed with $\mathrm{CH}_{2} \mathrm{Cl}_{2}$, and 
after activation in vacuum oven was reused in the next run.

\section{Results and discussion}

\subsection{Immobilization of the phosphotungstic acid into the mesopores of $S B A-16$}

Immobilization of Keggin-type phosphotungstic acid (PTA) into the mesopores of SBA-16 was achieved with encapsulation method. Due to the larger pore entrance size of SBA-16 than the size of PTA molecules, the leaching of the PTA molecules out of the mesopores during the catalytic reactions is probable. Hence, the pore entrance size of SBA-16 should be adjusted to be small enough to inhibit the escape of PTA molecules from the mesopores. For this purpose, the prepared material in the first step was reacted with triethoxyoctylsilane to modify the pore entrance size of the SBA-16. Earlier work by $\mathrm{Li}$ et al. showed that silylation with this reagent resulted in reducing the pore entrance rather than pore blocking [50].

\subsection{Characterization of the prepared material} In order to approve the immobilization of the PTA into the mesopores of SBA-16, the FT-IR spectra were acquired and studied. FT-IR spectra of pure PTA, SBA-16, and encapsulated PTA into the mesopores of SBA-16, PTA@SBA-16, are shown in Figure 1. In the FT-IR spectrum of pure PTA Figure 1(a), the band at $1080 \mathrm{~cm}^{-1}$ is attributed to the $\mathrm{P}=\mathrm{O}$ asymmetric vibration of $\mathrm{PO}_{4}$ unit, whereas the bands at 982,893 , and $798 \mathrm{~cm}^{-1}$ are assigned to the stretching modes of the terminal $\mathrm{W}=\mathrm{O}$, edge sharing $\mathrm{W}-\mathrm{O}_{\mathrm{e}}-\mathrm{W}$, and corner sharing $\mathrm{W}-\mathrm{O}_{\mathrm{c}}-\mathrm{W}$ units, respectively [55]. The FT-

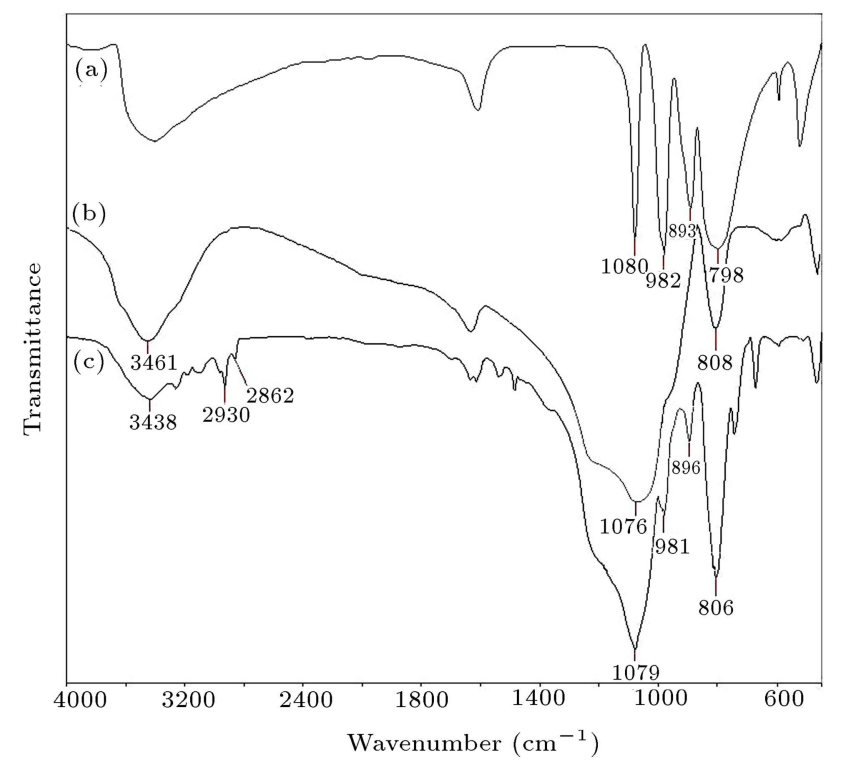

Figure 1. FT-IR spectra of (a) phosphotungstic acid, (b) SBA-16, and (c) PTA@SBA-16.
IR spectrum of pristine SBA-16 Figure 1(b) exhibits the asymmetric and symmetric stretching vibrations of $\mathrm{Si}-\mathrm{O}-\mathrm{Si}$ at $1076 \mathrm{~cm}-1$ and $808 \mathrm{~cm}^{-1}$, respectively $[49,53]$. In the FT-IR spectrum of PTA@SBA16 Figure 1(c), the characteristic bands of Keggintype phosphotungstic acid in PTA@SBA-16 are similar to those of the unsupported one. The $\mathrm{P}=\mathrm{O}$ stretching band in the PTA@SBA-16 sample is not clearly identified due to the overlap with the broad Si-O-Si band at $1079 \mathrm{~cm}^{-1}$. However, the bands at 981, 896, and $806 \mathrm{~cm}^{-1}$ are clearly observed for PTA@SBA-16, which can be attributed to the stretching modes of the terminal $\mathrm{W}=\mathrm{O}$, edge sharing $\mathrm{W}-\mathrm{O}_{\mathrm{e}}-\mathrm{W}$, and corner sharing $\mathrm{W}-\mathrm{O}_{\mathrm{c}}-\mathrm{W}$ units of phosphotungstic acid, respectively. The observation of these bands after soxhlet extraction of the prepared material and elimination of physisorbed species indicates that phosphotungstic acid species are successfully entrapped into the SBA-16 support. On the other hand, the peaks in the range of $2800-3000 \mathrm{~cm}^{-1}$ are due to $\mathrm{C}-\mathrm{H}$ stretching vibrations of octyl groups, confirming the successful silylation of the material. The decrease in the intensity of the broad band in the range of $3200-3700 \mathrm{~cm}^{-1}$ indicates that a portion of silanol groups is consumed due to the silylation reaction.

ICP-OES measurements show that the soxhlet extracted PTA@SBA-16 material contains 0.069 mmol phosphotungstic acid per gram of SBA-16 and, further, approve its encapsulation into the mesopores of SBA-16.

Low-angle powder X-Ray Diffraction (XRD) patterns of SBA-16 and PTA@SBA-16 are shown in Figure 2. The comparison of the patterns indicates the structural preservation upon encapsulation of PTA molecules. Immobilization of the PTA molecules into the mesopores of SBA-16 host reduces the order of mesostructured system. Thus, a decrease in the intensity of the peak in the low-angle region is observed. The characteristic peaks of PTA were not observed in the wide angle region, which can be ascribed to the fine

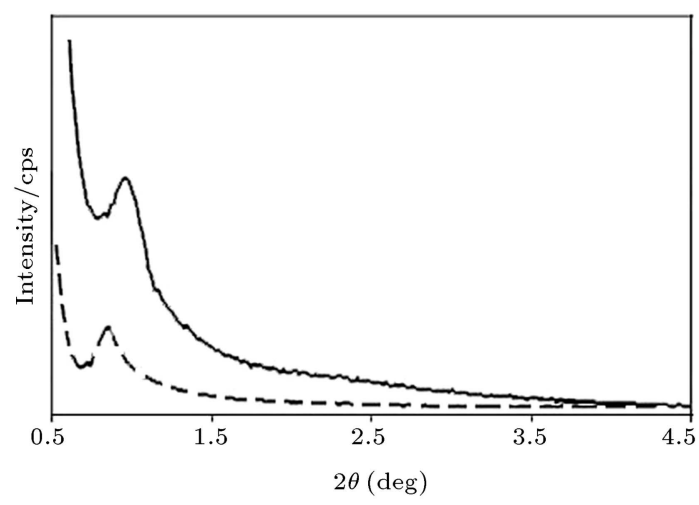

Figure 2. XRD patterns of SBA-16 (solid line) and PTA@SBA-16 (dashed line). 


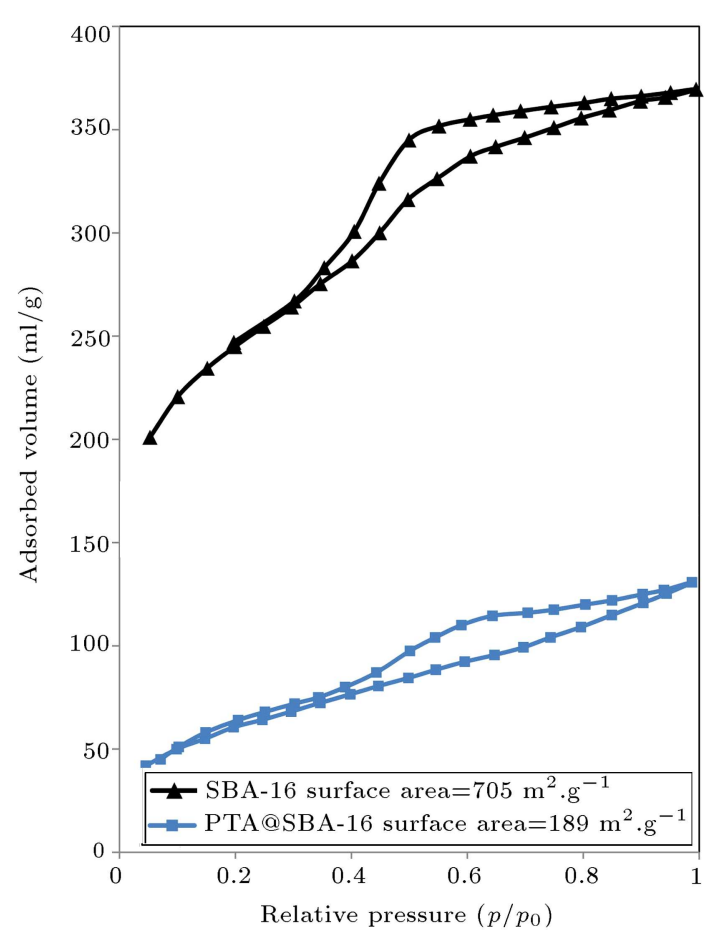

Figure 3. Nitrogen sorption isotherms of SBA-16 and PTA@SBA-16.

dispersion of the PTA species within the mesopores of SBA-16.

To explore the changes in the pore structure of SBA-16 after encapsulation of PTA species, $\mathrm{N}_{2}$ adsorption-desorption experiment was carried out at liquid $\mathrm{N}_{2}$ temperature; the isotherms are shown in Figure 3. As can be seen, pristine SBA-16 shows type IV isotherm with $\mathrm{H}_{2}$ hysteresis loop in compliance to the Brunauer-Deming-Deming-Teller (BDDT) classification, which is characteristic of a cage-like cubic mesoporous structure [48,49]. The PTA@SBA16 also shows type IV isotherm with $\mathrm{H}_{2}$ hysteresis loop, approving that this material still preserves the cubic cage-like mesoporous structure of the SBA16. In comparison with SBA-16, adsorbed volume of PTA@SBA-16 decreases, which indicates that the pore size is reduced by encapsulation of PTA molecules.

The surface areas of the materials were obtained by BET (Brunauer, Emmett, and Teller) method (as indicated in the Figure 3). It was found that in comparison with pristine SBA-16, the surface area of the PTA@SBA-16 sample decreased, which confirmed the presence of PTA species in the mesopores of SBA-16.

Transmission Electron Microscopy (TEM) analysis was applied to investigate the extent of order in PTA@SBA-16 as well as the uniformity of mesopores (Figure 4). The pore diameter of the sample estimated from the TEM image measures about $4 \mathrm{~nm}$. The TEM micrograph demonstrates that the ordered channel structure of SBA-16 has been preserved after encapsulation of PTA molecules.

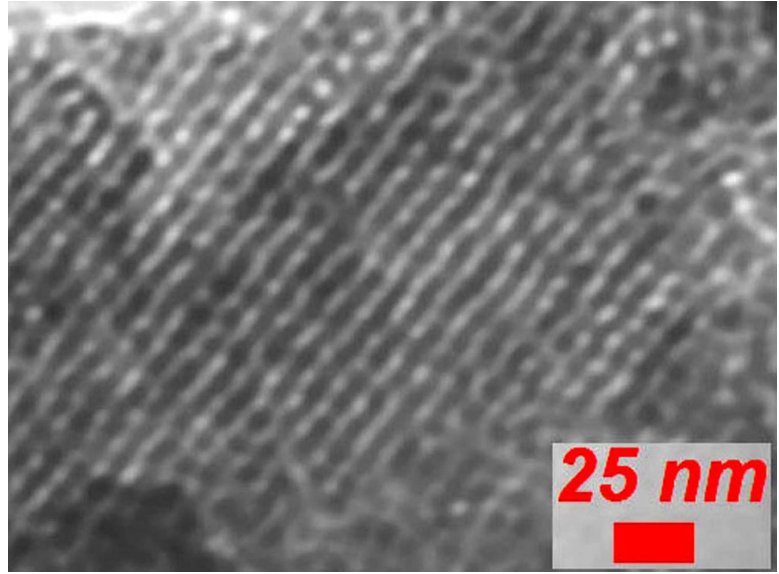

Figure 4. TEM image of the prepared PTA@SBA-16.

\subsection{Catalytic activities of the prepared catalyst}

The catalytic performance of the resultant PTA@SBA16 was assessed in the epoxidation of olefins and allylic alcohols using aqueous $30 \% \mathrm{H}_{2} \mathrm{O}_{2}$. Firstly, the effect of various amounts of $\mathrm{H}_{2} \mathrm{O}_{2}$ on the epoxidation of cyclooctene was studied of which the results are shown in Table 1. As can be seen, the conversion of cyclooctene increases with increase in the $\mathrm{H}_{2} \mathrm{O}_{2}$ :cyclooctene ratio. Due to the nonproductive decomposition of $\mathrm{H}_{2} \mathrm{O}_{2}$ in the course of the reaction, it is required to use excess value of $\mathrm{H}_{2} \mathrm{O}_{2}$ with respect to the olefins. Thus, the epoxidation reactions were conducted with $\mathrm{H}_{2} \mathrm{O}_{2}$ :olefin ratio of $1.6: 1$ of which the results are shown in Figure 5.

The catalytic system was found to be highly active and selective (close to 100\%) toward the epoxide formation. As seen in Figure 5, the olefins with higher electronic density of the double bond were more reactive in the epoxidation reaction. Based on the epoxidation mechanism (Figure 6) suggested in literature [56,57], higher electron donating ability of olefin double bond is predicted, hence accelerating the rate of epoxidation. As shown in the proposed mechanism of epoxidation reaction, the active site in the catalyst (peroxygen

Table 1. Investigation of the effect of the amount of hydrogen peroxide on the catalytic epoxidation of cyclooctene.

\begin{tabular}{cccc}
\hline $\begin{array}{c}\text { Run } \\
\text { no. }\end{array}$ & $\begin{array}{c}\mathbf{H}_{2} \mathbf{O}_{2} \\
(\mathbf{m m o l})\end{array}$ & $\begin{array}{c}\text { Conversion }^{\text {a }} \\
(\boldsymbol{\%})\end{array}$ & $\begin{array}{c}\text { Selectivity }^{\mathbf{b}} \\
(\boldsymbol{\%})\end{array}$ \\
\hline 1 & 8 & 46 & $>99$ \\
2 & 10 & 59 & $>99$ \\
3 & 12.8 & 74 & $>99$ \\
\hline
\end{tabular}

Reaction conditions: Catalyst: $100 \mathrm{mg}$, Cyclooctene: $8 \mathrm{mmol}$, refluxing: $\mathrm{CH}_{3} \mathrm{CN} 10 \mathrm{ml}$, time: $8 \mathrm{~h}$.

a Based on consumed cyclooctene;

b Selectivity toward epoxycyclooctane. 


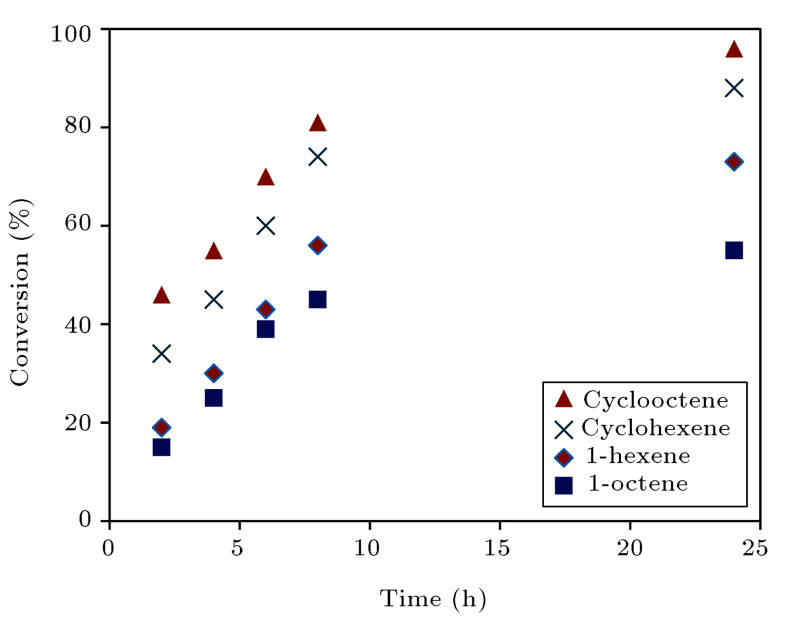

(a)

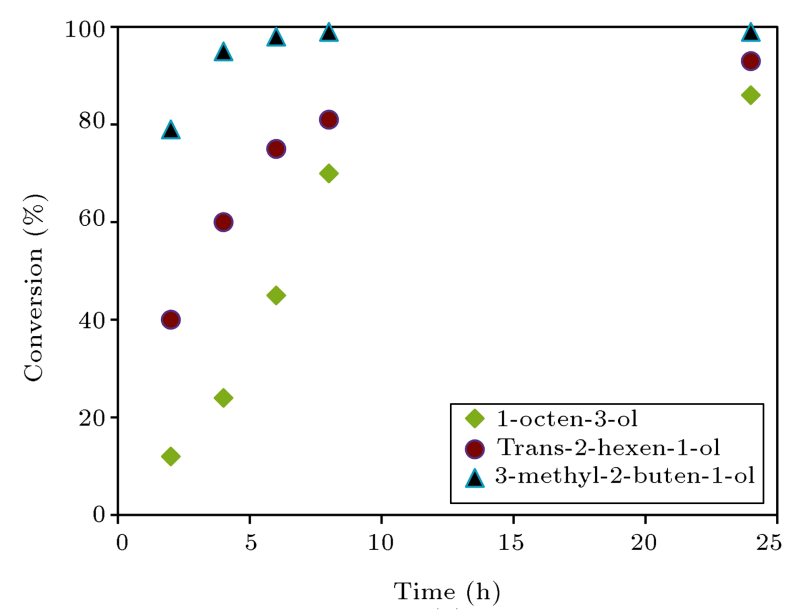

(b)

Figure 5. Results of catalytic epoxidation of some olefins and allylic alcohols with $\mathrm{H}_{2} \mathrm{O}_{2}$ in the presence of PTA@SBA-16. Reaction conditions: Catalyst (100 mg), Olefin $(8 \mathrm{mmol}), \mathrm{H}_{2} \mathrm{O}_{2}(12.8 \mathrm{mmol})$, refluxing $\mathrm{CH}_{3} \mathrm{CN}$ $(10 \mathrm{ml})$.

center) has electrophilic character and the mechanism of oxygen transfer to the olefin is electrophilic attack of electron deficient oxygen to the olefin double bond as nucleophilic species. Therefore, more nucleophilic character of the double bond promotes the epoxidation reaction. On the other hand, due to the participation

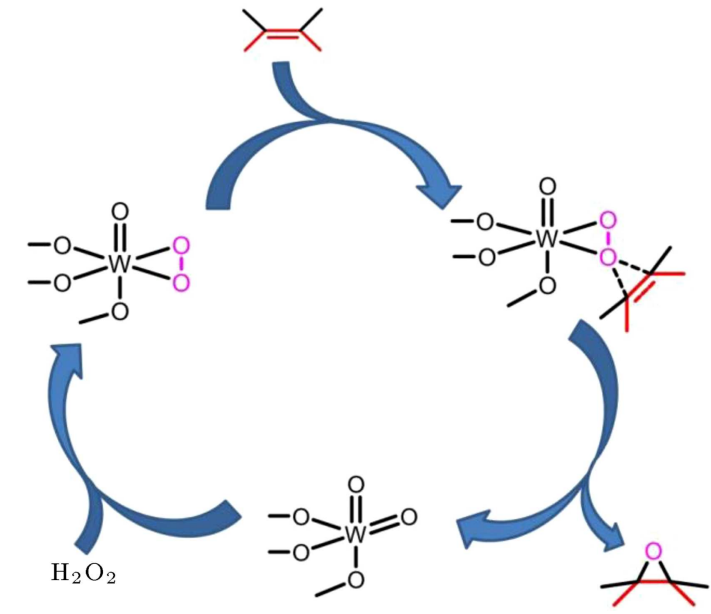

Figure 6. Mechanism of epoxidation of olefins with $\mathrm{H}_{2} \mathrm{O}_{2}$ in the presence of PTA@SBA-16.

of hydroxyl group in drawing the double bond toward the electrophilic peroxygen center, allylic alcohols are more reactive than simple olefins.

Blank reaction (without the catalyst) was also carried out to specify the role of the catalyst (Table 2). Very low conversion was achieved in the absence of catalyst. Similar epoxidation reaction was carried out with pristine SBA-16 and negligible catalytic activity was evidenced. These results confirm the catalytic effect of the immobilized phosphotungstic acid.

The catalytic properties of the prepared heterogeneous catalyst (PTA@SBA-16) were compared with those of the corresponding homogeneous analogue, i.e. phosphotungstic acid, under the same reaction conditions (Table 2). As can be seen in this table, the reaction rate by using of the prepared heterogeneous catalyst was comparable to that by using the homogeneous one. The results indicate that catalytic performance of the heterogeneous catalyst is related to fine dispersion of the active catalytic species within the mesopores of SBA-16.

On the other hand, in order to evaluate the probable catalytic contribution of the leached PTA species in the epoxidation of cyclooctene, the reaction mixture was filtered off after $2 \mathrm{~h}$ and the filtrate was left to react for a further $24 \mathrm{~h}$. As can be seen in

Table 2. Epoxidation of cyclooctene with $\mathrm{H}_{2} \mathrm{O}_{2}$ in different conditions.

\begin{tabular}{cccccc}
\hline $\begin{array}{c}\text { Run } \\
\text { no. }\end{array}$ & Catalyst & $\begin{array}{c}\text { Catalyst } \\
\text { amount }(\mathbf{m g})\end{array}$ & $\begin{array}{c}\text { Time } \\
(\mathbf{h})\end{array}$ & $\begin{array}{c}\text { Conversion } \\
(\boldsymbol{\%})\end{array}$ & $\begin{array}{c}\text { Selectivity }^{\text {a }} \\
(\boldsymbol{\%})\end{array}$ \\
\hline 1 & SBA-16 & $100 \mathrm{mg}$ & 24 & 12 & 62 \\
2 & - & - & 24 & 5 & 56 \\
3 & $\mathrm{H}_{3} \mathrm{PW}_{12} \mathrm{O}_{40}$ & $10 \mathrm{mg}$ & 2 & 18 & $>99$ \\
& & & 8 & 70 & $>99$ \\
& & & 24 & 97 & $>99$ \\
\hline
\end{tabular}

Reaction conditions: Cyclooctene: $8 \mathrm{mmol}, \mathrm{H}_{2} \mathrm{O}_{2}: 12.8 \mathrm{mmol}$, refluxing $\mathrm{CH}_{3} \mathrm{CN}: 10 \mathrm{ml}$.

a Selectivity toward epoxycyclooctane. 
Table 3. Investigation of the catalytic contribution of the possibly solubilized heteropoly acid species.

\begin{tabular}{ccccc}
\hline Run no. & & $\begin{array}{c}\text { Time } \\
(\mathbf{h})\end{array}$ & $\begin{array}{c}\text { Conversion } \\
(\%)\end{array}$ & $\begin{array}{c}\text { Selectivity }^{\mathbf{a}} \\
(\%)\end{array}$ \\
\hline 1 & $\begin{array}{c}\text { Before filtering } \\
\text { the catalyst }\end{array}$ & 2 & 46 & $>99$ \\
& $\begin{array}{c}\text { After filtering } \\
\text { the catalyst }\end{array}$ & 24 & 50 & 99 \\
\hline
\end{tabular}

Reaction conditions: Catalyst: $100 \mathrm{mg}$, cyclooctene: $8 \mathrm{mmol}$,

$\mathrm{H}_{2} \mathrm{O}_{2}: 12.8$ mmol, refluxing acetonitrile: $10 \mathrm{ml}$.

${ }^{a}$ Selectivity toward epoxycyclooctane.

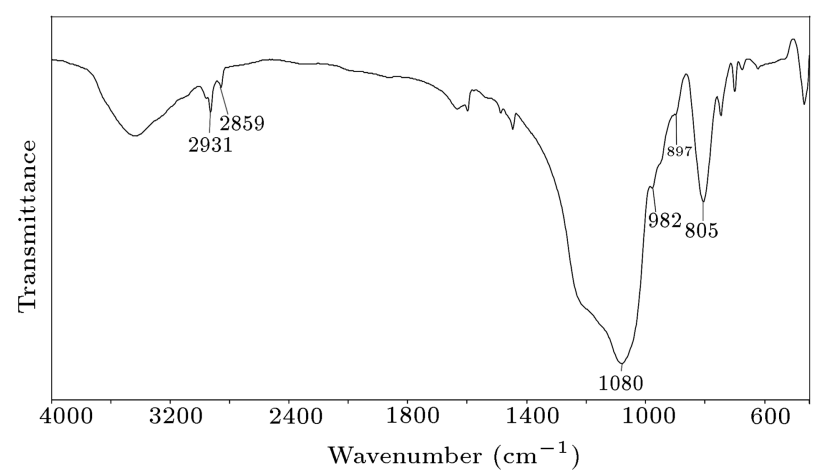

Figure 7. FT-IR spectrum of the recovered PTA@SBA-16.

Table 3, in this time span, the conversion of cyclooctene increased by only $4 \%$, suggesting that the epoxidation reaction was nearly stopped by the elimination of the catalyst, and there was no tungsten species in the solution. Moreover, after filtration of the reaction mixture, the solid catalyst was characterized by FT-IR spectroscopy and the tungsten content of the filtrate was also analyzed by ICP-OES. It was found that the quantity of tungsten species in the aqueous phase was negligible. Furthermore, the FT-IR spectrum of the recovered catalyst (Figure 7 ) showed no change in comparison with fresh PTA@SBA-16 catalyst. Therefore, it can be concluded that the catalytic reaction is really heterogeneous.

The reusability of PTA@SBA-16 was inspected in the epoxidation of 3-methyl-2-butene-1-ol with $30 \%$ $\mathrm{H}_{2} \mathrm{O}_{2}$ of which the results are shown in Figure 8. After each run, the catalyst was isolated from the reaction mixture, washed several times with acetonitrile, and dried before using in the subsequent run. As can be seen in Figure 8, the catalytic activity decreased very slightly during the later runs. Thus, it can be concluded that the catalyst is recoverable and reusable for at least two times in the epoxidation of olefins.

Comparison of these results with our recently published work on the catalyst derived from the immobilization of $\mathrm{H}_{6} \mathrm{P}_{2} \mathrm{~W}_{18} \mathrm{O}_{62}$ compound with WellsDawson structure into the SBA-16 [53], shows that the Keggin-type structure, i.e. PTA@SBA-16, has compa-

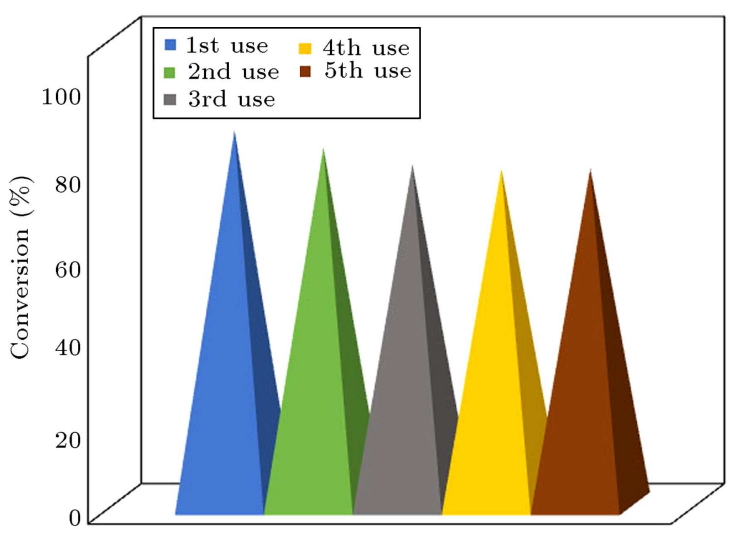

Figure 8. Results of catalytic epoxidation of 3-methyl-2-butene-1-ol with $\mathrm{H}_{2} \mathrm{O}_{2}$ in the presence of recycled PTA@SBA-16. Reaction conditions: catalyst: $100 \mathrm{mg}$, olefin: $8 \mathrm{mmol}, \mathrm{H}_{2} \mathrm{O}_{2}: 12.8 \mathrm{mmol}$, refluxing $\mathrm{CH}_{3} \mathrm{CN}: 10 \mathrm{ml}$

rable (e.g., in the case of cyclooctene and cyclohexene) or even higher (e.g., in the case of 1-octene and 1hexene) activities in the epoxidation of olefins. On the other hand, as the preparation of Keggin-type structure is easier than that of the Wells-Dawson one, the present catalyst is preferred in practical epoxidation of olefins.

\section{Conclusion}

This work provided an efficient and easy method for immobilization of Keggin-type phosphotungstic acid into the mesopores of SBA-16. The heteropoly acid was confined onto the SBA-16 support by, first, encapsulation and, then, reducing the pore entrance size with silylation reagent. ICP-OES and FT-IR spectroscopies confirmed the immobilization of phosphotungstic acid. XRD and TEM analyses revealed that the structure of mesoporous support was preserved after immobilization of phosphotungstic acid. The prepared material can be efficiently used as active, selective, and environmentally benign catalyst for the epoxidation of olefins. It was shown that the catalyst was really heterogeneous and reusable, which could be used at least two times without considerable loss of activity. 


\section{Acknowledgment}

The authors are grateful to Kharazmi University for financial support.

\section{References}

1. Pope, M.T. Heteropoly and Isopoly Oxometalates, Springer Verlag (1983).

2. Moffat, J.B. Metal-oxygen Clusters: the Surface and Catalytic Properties of Heteropoly Oxometalates, Springer Science \& Business Media (2006).

3. Long, D.L., Burkholder, E. and Cronin, L. "Polyoxometalate clusters, nanostructures and materials: from self assembly to designer materials and devices", Chem. Soc. Rev., 36(1), pp. 105-121 (2007).

4. Müller, A., Peters, F., Pope, M.T. and Gatteschi, D. "Polyoxometalates: very large clusters nanoscale magnets", Chem. Rev., 98(1), pp. 239-272 (1998).

5. Kozhevnikov, I.V., Catalysts for Fine Chemical Synthesis, Catalysis by Polyoxometalates, 2, Wiley (2002).

6. Katsoulis, D.E. "A survey of applications of polyoxometalates", Chem. Rev., 98(1), pp. 359-388 (1998).

7. Zhou, Y., Chen, G., Long, Z. and Wang, J. "Recent advances in polyoxometalate-based heterogeneous catalytic materials for liquid-phase organic transformations", RSC Adv., 4(79), pp. 42092-42113 (2014).

8. Mizuno, N. and Misono, M. "Heterogeneous catalysis", Chem. Rev., 98(1), pp. 199-218 (1998).

9. Kozhevnikov, I.V. "Catalysis by heteropoly acids and multicomponent polyoxometalates in liquid-phase reactions", Chem. Rev., 98(1), pp. 171-198 (1998).

10. Mizuno, N., Kamata, K. and Yamaguchi, K. "Green oxidation reactions by polyoxometalate-based catalysts: from molecular to solid catalysts", Top. Catal., 53(13-14), pp. 876-893 (2010).

11. Mizuno, N. and Kamata, K. "Catalytic oxidation of hydrocarbons with hydrogen peroxide by vanadium-based polyoxometalates", Coord. Chem. Rev., 255(19), pp. 2358-2370 (2011).

12. Kholdeeva, O., Maksimchuk, N. and Maksimov, G. "Polyoxometalate-based heterogeneous catalysts for liquid phase selective oxidations: Comparison of different strategies", Catal. Today, 157(1), pp. 107-113 (2010).

13. Li, G., Ding, Y., Wang, J., Wang, X. and Suo, J. "New progress of Keggin and Wells-Dawson type polyoxometalates catalyze acid and oxidative reactions", $J$. Mol. Catal. A: Chem., 262(1), pp. 67-76 (2007).

14. Weinstock, I.A. "Homogeneous-phase electron-transfer reactions of polyoxometalates", Chem. Rev., 98(1), pp. 113-170(1998).

15. Vasylyev, M.V. and Neumann, R. "New heterogeneous polyoxometalate based mesoporous catalysts for hydrogen peroxide mediated oxidation reactions", J. Am. Chem. Soc., 126(3), pp. 884-890 (2004).
16. Mizuno, N., Yamaguchi, K. and Kamata, K. "Epoxidation of olefins with hydrogen peroxide catalyzed by polyoxometalates", Coord. Chem. Rev., 249(17), pp. 1944-1956 (2005).

17. Venturello, C. and D Aloisio, R. "Quaternary ammonium tetrakis (diperoxotungsto) phosphates (3-) as a new class of catalysts for efficient alkene epoxidation with hydrogen peroxide", J. Org. Chem., 53(7), pp. 1553-1557 (1988).

18. Kamata, K., Yonehara, K., Sumida, Y., Yamaguchi, K., Hikichi, S. and Mizuno, N. "Efficient epoxidation of olefins with $99 \%$ selectivity and use of hydrogen peroxide", Science, 300(5621), pp. 964-966 (2003).

19. Dufaud, V. and Lefebvre, V. "Inorganic hybrid materials with encapsulated polyoxometalates", Materials, 3(1), pp. 682-703 (2010).

20. Wee, L.H., Bonino, F., Lamberti, C., Bordiga, S. and Martens, J.A. "Cr-MIL-101 encapsulated Keggin phosphotungstic acid as active nanomaterial for catalysing the alcoholysis of styrene oxide", Green Chem., 16(3), pp. 1351-1357 (2014).

21. Sun, C.Y., Liu, S.X., Liang, D.D., Shao, K.Z., Ren, Y.H. and Su, Z.M. "Highly stable crystalline catalysts based on a microporous metal-organic framework and polyoxometalates", J. Am. Chem. Soc., 131(5), pp. 1883-1888 (2009).

22. Maksimchuk, N., Timofeeva, M., Melgunov, M., Shmakov, A., Chesalov, Y.A., Dybtsev, D., Fedin, V. and Kholdeeva, O. "Heterogeneous selective oxidation catalysts based on coordination polymer MIL-101 and transition metal-substituted polyoxometalates", $J$. Catal., 257(2), pp. 315-323 (2008).

23. Maksimchuk, N.V., Kovalenko, K.A., Arzumanov, S.S., Chesalov, Y.A., Melgunov, M.S., Stepanov, A.G., Fedin, V.P. and Kholdeeva, O.A. "Hybrid polyoxotungstate/MIL-101 materials: synthesis, characterization, and catalysis of $\mathrm{H}_{2} \mathrm{O}_{2}$-based alkene epoxidation", Inorg. Chem., 49(6), pp. 2920-2930 (2010).

24. Juan-Alcaniz, J., Ramos-Fernandez, E.V., Lafont, U., Gascon, J. and Kapteijn, F. "Building MOF bottles around phosphotungstic acid ships: one-pot synthesis of bi-functional polyoxometalate-MIL-101 catalysts", J. Catal., 269(1), pp. 229-241 (2010).

25. Hu, X., Lu, Y., Dai, F., Liu, C. and Liu, Y. "Hostguest synthesis and encapsulation of phosphotungstic acid in MIL-101 via "bottle around ship": an effective catalyst for oxidative desulfurization", Micropor. Mesopor. Mater., 170, pp. 36-44 (2013).

26. Zhang, F., Yuan, C., Wang, J., Kong, Y., Zhu, H. and Wang, C. "Synthesis of fructone over dealmuinated USY supported heteropoly acid and its salt catalysts", J. Mol. Catal. A: Chem., 247(1), pp. 130-137 (2006).

27. Pamin, K., Kubacka, A., Olejniczak, Z., Haber, J. and Sulikowski, B. "Immobilization of dodecatungstophosphoric acid on dealuminated zeolite Y: a physicochemical study", Appl. Catal. A: Gen., 194, pp. 137-146 (2000). 
28. Jin, D., Gao, J., Hou, Z., Guo, Y., Lu, X., Zhu, Y. and Zheng, $\mathrm{X}$. "Microwave assisted in situ synthesis of USY-encapsulated heteropoly acid (HPW-USY) catalysts", Appl. Catal. A: Gen., 352(1), pp. 259-264 (2009).

29. Sulikowski, B. and Rachwalik, R. "Catalytic properties of heteropoly acid/zeolite hybrid materials: toluene disproportionation and transalkylation with 1,2,4trimethylbenzene", Appl. Catal. A: Gen., 256(1), pp. 173-182 (2003).

30. Ozer, R.R. and Ferry, J.L. "Photocatalytic oxidation of aqueous 1,2-dichlorobenzene by polyoxometalates supported on the NaY zeolite", J. Phys. Chem. B, 106(16), pp. 4336-4342 (2002).

31. Rao, P.M., Wolfson, A., Kababya, S., Vega, S. and Landau, M. "Immobilization of molecular $\mathrm{H}_{3} \mathrm{PW}_{12} \mathrm{O}_{40}$ heteropolyacid catalyst in alumina-grafted silica-gel and mesostructured SBA-15 silica matrices", J. Catal., 232(1), pp. 210-225 (2005).

32. Tan, R., Liu, C., Feng, N., Xiao, J., Zheng, W., Zheng, A. and Yin, D. "Phosphotungstic acid loaded on hydrophilic ionic liquid modified SBA-15 for selective oxidation of alcohols with aqueous $\mathrm{H}_{2} \mathrm{O}_{2}$ ", Micropor. Mesopor. Mater., 158, pp. 77-87 (2012).

33. Gagea. B., Lorgouilloux, Y., Altintas, Y., Jacobs, P. and Martens, J. "Bifunctional conversion of n-decane over HPW heteropoly acid incorporated into SBA-15 during synthesis", J. Catal., 265(1), pp. 99-108 (2009).

34. Villanneau, R., Marzouk, A., Wang, Y., Djamaa, A.B., Laugel, G., Proust, A. and Launay, F. "Covalent grafting of organic-inorganic polyoxometalates hybrids onto mesoporous SBA-15: a key step for new anchored homogeneous catalysts", Inorg. Chem., 52(6), pp. 2958-2965 (2013).

35. Tang, J., Wang, L., Liu, G., Liu, Y., Hou, Y., Zhang, W., Jia, M. and Thiel, W. R. "Mesoporous SBA-15 materials modified with oxodiperoxo tungsten complexes as efficient catalysts for the epoxidation of olefins with hydrogen peroxide", J. Mol. Catal. A: Chem., 313(1), pp. 31-37(2009).

36. Wu, S., Wang, J., Zhang, W. and Ren, X. "Preparation of Keggin and Preyssler heteropolyacid catalysts on amine-modified SBA-15 and their catalytic performances in esterification of n-butanol with acetic acid", Catal. Lett., 125(3-4), pp. 308-314 (2008).

37. Wu, Q., Jin, H., Feng, W. and Pang, W. "Preparation and conductivity of decatungstomolybdovanadogermanic heteropoly acid supported on mesoporous silica SBA-15, SBA-16, MCM-41 and MCM-48", Stud. Surf. Sci. Catal., pp. 847-851 (2007).

38. Inumaru, K., Ishihara, T., Kamiya, Y., Okuhara, T. and Yamanaka, S. "Water-tolerant, highly active solid acid catalysts composed of the keggin-type polyoxometalate $\mathrm{H}_{3} \mathrm{PW}_{12} \mathrm{O}_{40}$ immobilized in hydrophobic nanospaces of organomodified mesoporous silica", Angew. Chem. Int. Ed., 46(40), pp. 7625-7628 (2007).
39. Juan, J.C., Zhang, J. and Yarmo, M.A. "12Tungstophosphoric acid supported on MCM-41 for esterification of fatty acid under solvent-free condition", J. Mol. Catal. A: Chem., 267(1), pp. 265-271 (2007).

40. Nowinska, K. and Kaleta, W. "Synthesis of BisphenolA over heteropoly compounds encapsulated into mesoporous molecular sieves", Appl. Catal. A: Gen., 203(1), pp. 91-100 (2000).

41. Carriazo, D., Domingo, C., Martín, C. and Rives, V. "PMo or PW heteropoly acids supported on MCM-41 silica nanoparticles: Characterisation and FT-IR study of the adsorption of 2-butanol", J. Solid State Chem., 181(8), pp. 2046-2057 (2008).

42. Abd El Rahman, S.K., Hassan, H.M. and El-Shall, M.S. "Acid catalyzed organic transformations by heteropoly tungstophosphoric acid supported on MCM41", Appl. Catal. A: Gen., 411, pp. 77-86 (2012).

43. Jermy, B.R. and Pandurangan, A. " $\mathrm{H}_{3} \mathrm{PW}_{12} \mathrm{O}_{40}$ supported on MCM-41 molecular sieves: An effective catalyst for acetal formation", Appl. Catal. A: Gen., 295(2), pp. 185-192 (2005).

44. Llanos, A., Melo, L., Avendano, F., Montes, A. and Brito, J.L. "Synthesis and characterization of HPW/MCM-41 ( $\mathrm{Si}$ ) and HPW/MCM-41 (Si/Al) catalysts: Activity for toluene alkylation with 1-dodecene", Catal. Today, 133, pp. 20-27 (2008).

45. Kozhevnikov, I.V., Sinnema, A., Jansen, R.J.J., Pamin, K. and Van Bekkum, H. "New acid catalyst comprising heteropoly acid on a mesoporous molecular sieve MCM-41", Catal. Lett., 30(1-4), pp. 241-252 (1994).

46. Kozhevnikov, I.V., Kloetstra, K., Sinnema, A., Zandbergen, H. and Van Bekkum, H. "Study of catalysts comprising heteropoly acid $\mathrm{H}_{3} \mathrm{PW}_{12} \mathrm{O}_{40}$ supported on MCM-41 molecular sieve and amorphous silica", $J$. Mol. Catal. A: Chem., 114(1), pp. 287-298 (1996).

47. Verhoef, M.J., Kooyman, P.J., Peters, J.A. and Van Bekkum, H. "A study on the stability of MCM-41supported heteropoly acids under liquid-and gas-phase esterification conditions", Micropor. Mesopor. Mater., 27(2), pp.365-371 (1999).

48. Yu, C., Tian, B., Fan, J., Stucky, G.D. and Zhao, D. "Nonionic block copolymer synthesis of large-pore cubic mesoporous single crystals by use of inorganic salts", J. Am. Chem. Soc., 124(17), pp. 4556-4557 (2002).

49. Sun, H., Tang, Q., Du, Y., Liu, X., Chen, Y. and Yang, Y. "Mesostructured SBA-16 with excellent hydrothermal, thermal and mechanical stabilities: Modified synthesis and its catalytic application", J. Colloid Interface Sci., 333(1), pp. 317-323(2009).

50. Yang, H., Zhang, L., Wang, P., Yang, Q. and Li, C. "The enantioselective cyanosilylation of aldehydes on a chiral VO (Salen) complex encapsulated in SBA-16", Green Chem., 11(2), pp. 257-264 (2009).

51. Bordoloi, A., Amrute, A.P. and Halligudi, S." $[\mathrm{Ru}($ salen)(NO)] complex encapsulated in mesoporous 
SBA-16 as catalyst for hydrogenation of ketones", Catal. Commun., 10(1), pp. 45-48 (2008).

52. Yang, H., Zhang, L., Su, W., Yang, Q. and Li, C. "Asymmetric ring-opening of epoxides on chiral $\mathrm{Co}$ (Salen) catalyst synthesized in SBA-16 through the "ship in a bottle" strategy", J. Catal., 248(2), pp. 204212 (2007).

53. Masteri-Farahani, M., Najafi, Gh.R., Modarres, M. and Taghvai-Nakhjiri, M. "Wells-Dawson heteropolyacid encapsulated into the nanocages of SBA-16 as heterogeneous catalyst for the oxidation of olefins and alcohols", J. Porous Mater., 23(1), pp. 285-290 (2016).

54. Masteri-Farahani, M. and Modarres, M., "WellsDawson heteropoly acid immobilized inside the nanocages of SBA-16 with ship-in-a-bottle method: A new recoverable catalyst for the epoxidation of olefins" J. Mol. Catal. A: Chem. 417(1) pp. 81-88 (2016).

55. Rocchiccioli-Deltcheff, C., Fournier, M., Franck, R. and Thouvenot, R. "Vibrational investigations of polyoxometalates. 2. Evidence for anion-anion interactions in molybdenum (VI) and tungsten (VI) compounds related to the Keggin structure", Inorg. Chem., 22(2), pp. 207-216 (1983).

56. Amato, G., Arcoria, A., Ballistreri, F.P., Tomaselli, G.A., Bortolini, O., Conte, V., Di Furia, F., Modena, G. and Valle, G. "Oxidations with peroxotungsten complexes: rates and mechanism of stoichiometric olefin epoxidations", J. Mol. Catal., 37(2), pp. 165175 (1986).

57. Jorgensen, K.A. "Transition-metal-catalyzed epoxidations", Chem. Rev., 89(3), pp. 431-458 (1989).

\section{Biographies}

Majid Masteri-Farahani was born in 1976. He received his BSc degree in Chemistry from University of Tehran in 1998. He obtained his MSc degree and $\mathrm{PhD}$ in Inorganic Chemistry under direction of Professor Mahdi Ghandi and Professor Faezeh Farzaneh from University of Tehran in 2001 and 2006, respectively. After that, he joined the Faculty of Chemistry at Kharazmi University in 2006. His current research interests include preparation and characterization of new hybrid materials and catalysts.

Maryam Modarres was born in 1986. She received her BSc degree in Chemistry from University of Yasuj in 2009 and MSc in Inorganic Chemistry under the direction of Dr. Majid Masteri-Farahani from Kharazmi University in 2012. She is currently $\mathrm{PhD}$ student in Inorganic Chemistry at Kharazmi University and works on the preparation and characterization of hetereogenized polyoxometalate catalysts. 